\title{
TÃO LONGE, TÃO PERTO: ESCRITA DE SI EM RELATÓRIOS DE VIAGENS
}

\author{
Ana Chrystina Venancio Mignot* \\ Alexandra Lima da Silva**
}

RESUMO: Explorar os sentidos de um tom autobiográfico inscrito em relatórios de viagens empreendidas por três professores que integravam a primeira missão oficial de educadores que visitaria o continente europeu, no alvorecer da República, com a finalidade de estudar o sistema educacional de vários países, é o horizonte deste texto. Tais experiências compunham as preocupações com as melhorias na instrução pública no país, em que as viagens para conhecer e estudar o outro, divulgadas e defendidas pela Revista Pedagógica, publicação do Pedagogium, revertiam-se em diferentes modos de intervir e propor mudanças na educação no Brasil. Procura-se, nesta análise, em meio à escrita obrigatória e fadada à impessoalidade, mais do que impressões, conclusões e proposições sobre a organização escolar, a organização do magistério, o material didático, a arquitetura das escolas e os aspectos relativos à remuneração dos professores, mas, sobretudo, os traços da intimidade e dos modos de ver o mundo dos professores viajantes.

Palavras-chave: Viagens de Educadores; Relatórios de Viagens; Escrita de Si.

\section{SO FAR, SO CLOSE: WRITINGS ABOUT ONESELF IN TRAVEL REPORTS}

ABSTRACT: This text explores the meanings and senses of autobiographical travel reports written by three professors, members of the first official educators' committee visiting Europe at the dawn of the Brazilian Republican regime. Their goal was to study the national education systems of several countries. This experience reflected concerns regarding the improvement of Brazilian public education. At that time, trips organized by the "Revista Pedagógica" (Pedagogic Magazine), published by "Pedagogium", were organized in order to study the "other", resulting in different ways of intervention and change proposals for the Brazilian educational system. The present work examines through the mandatory impersonal writing style - more than mere impressions, conclusions and proposals for school organization, or the organization of teaching staff, school material, school architecture and aspects relating to teaching staff wages; above all, it examines the traces of intimacy and world views of the traveling professors.

Keywords: Educators' Trips; Traveling Reports; Own Writings.

* Professora Adjunta do Programa de Pós-Graduação em Educação da Universidade do Estado do Rio de Janeiro (UERJ); Pesquisadora do Conselho Nacional de Desenvolvimento Científico e Tecnológico (CNPq). E-mail: acmignot@terra.com.br * * Doutoranda Programa de Pós-Graduação em Educação da Universidade do Estado do Rio de Janeiro (UERJ) e Bolsista da FAPERJ. E-mail: alexandralima1075@gmail.com 
O que uma viagem pode revelar sobre aquele que viaja? É possível falar de si no encontro com o outro? Como a distância pode, ao mesmo tempo, aproximar? Explorar os sentidos de um tom autobiográfico inscrito em relatórios de viagens empreendidas por professores ${ }^{1}$ que integravam, no alvorecer da República, a primeira comissão oficial que visitaria o continente europeu ${ }^{2}$, com a finalidade de estudar o sistema educacional de vários países, é o horizonte deste texto.

Desta Comissão de Professores Primários à Europa e aos Estados Unidos fizeram parte Luiz Augusto dos Reis, Manoel José Pereira Frazão e Amélia Fernandes da Costa, que deixaram relatórios de viagens, documentos que, segundo Antonio Viñao, ${ }^{3}$ integram o amplo universo autobiográfico que interessa aos historiadores da educação que se voltam para o estudo do tempo pretérito, especialmente em estudos comparados.

Assim como os livros de viagens examinados pelo autor, os relatórios desses professores podem ser considerados autobiográficos, na medida em que não se limitam a narrar o visto e o vivido. Deixam escapar, algumas vezes, em meio à escrita obrigatória e fadada à impessoalidade, mais do que impressões, conclusões e proposições, marcas de si mesmos, de suas intimidades, de seus modos de ver o mundo.

Essa escrita circunstanciada, que deveria conter tudo o que fora “observado e estudado", era apenas mais uma das atribuições desses viajantes aos quais cabia:

1- Visitar as principais escolas primárias de Paris, Londres, Bruxelas, Berne, Genebra, Zurich, Milão e Turim, estudando a organização tanto das escolas urbanas como das suburbanas;

2- Visitar a escola de Naas na Suécia e acompanhar o curso de trabalhos manuais professado naquele estabelecimento;

3-Visitar as principais escolas de New York, Boston, Filadélfia e Washington, nos Estados Unidos;

4- Estudar cuidadosamente os métodos e material de ensino adotado em todos esses estabelecimentos, já quanto à educação física, já quanto a intelectual e moral;

5- Remeter a Inspetoria Geral da Instrução primaria e secundaria da Capital Federal, com quem se corresponderá diretamente, os programas minuciosos, os livros escolares, e quando possível, as plantas e fachadas de todas as boas escolas que tiver examinado, acompanhando-os das observações que entender convenientes;

6- Organizar e remeter trimestralmente a mesma Inspetoria Geral, um relatório circunstanciado do trabalho feito e de todo quanto houver observado e estudado. $\mathrm{O}$ 
professor comissionado dedicara, no maximo, ano e meio ao exame das escolas da Europa e quatro meses as dos Estados Unidos da América, recebendo para isso, desde o dia da partida até o de sua volta ao Rio de Janeiro, o seu vencimento integral de professor com a gratificação extraordinária de trezentos mil reis mensais, além da ajuda de custo de dois contos de reis, dada por sua vez para as despesas de viagem.

O professor se obriga depois de seu regresso ao Brasil, a servir pelo menos durante cinco anos na sua cadeira ou em qualquer cargo, que o governo julgue conveniente oferecer-lhe a bem de ensino. ${ }^{4}$

Os membros da comissão distinguiam-se daqueles que viajam por "puro prazer ou amor a cultura". Viajavam na e pela condição de professor, cabendo-lhes uma série de atribuições e encargos que outros viajantes não enfrentavam ${ }^{6}$. Profissionais comissionados deveriam visitar as escolas, observar e estudar os métodos, técnicas e arquitetura de locais de ensino, escrever relatórios descrevendo tudo, além de remeter os materiais e objetos interessantes para o ensino no Brasil. Tais atribuições sugerem pensar a viagem em missão oficial como parte de uma troca entre os envolvidos, no sentido de dom e contradom ${ }^{7}$, uma vez que, se, por um lado, recebia-se financiamento e custeio de hospedagem e deslocamentos, por outro, havia uma série de obrigações e encargos, no sentido de retribuir aqueles que financiavam a viagem.

Enquanto os escritos da viagem de Manoel José Pereira Frazão e Luiz Augusto Reis já foram estudados ${ }^{8}$, não localizamos estudos sobre a viagem de Amélia Fernandes da Costa, apesar de ela também ter publicado relatório sobre a experiência vivida em outros países, o que instiga a examinar a viagem dos três professores em conjunto, para que possamos, na comparação, obter um entendimento sobre suas escolhas e singularidades.

\section{Viagens e viajantes}

Os destinos dos três professores da referida comissão foram distintos. Enquanto Luiz Augusto dos Reis visitou Portugal, Espanha, França e Bélgica ${ }^{9}$, o professor M. J. Frazão teria se dedicado a cinco países, a saber: Itália, Suíça, Suécia, Inglaterra e França $a^{10}$. Por fim, a professora Amélia Fernandes da Costa visitou as escolas de três países: Itália, 
França e Bélgica ${ }^{11}$. Todavia, em que medida tais destinos esboçam ou representam as escolhas pessoais de cada um?

Temendo o rigoroso inverno europeu, Luiz Augusto dos Reis embarcara no Paquetá Magdalena da Mala Real Inglesa, a 30 de dezembro do ano de 1890. O destino inicial, Lisboa, também se deveu, em parte, à tentativa de escapar do frio, uma vez que "podia, pois, ser prejudicial a minha saúde e também, ao desempenho dos meus deveres uma transição tão brusca"12, segundo registro no qual manifesta uma preocupação não somente com suas condições físicas, mas também com as inúmeras obrigações inerentes à missão oficial.

A referida viagem, empreendida nos idos de 1890, deve ser entendida como um momento de uma vida. Nascido no Rio de Janeiro, em meados do século XIX, Luiz Augusto dos Reis começou a escrever muito cedo. Em 1874, publicou seu primeiro livro, Cantos e prantos, editado por Castro Dias Editor. O trabalho é dedicado à mãe: "A quem, senão a vós, devera dedicar este livro: cantos de minha infância, queixumes de minha alma triste. Nele se acha a história das minhas agonias; é ele o poema dos martírios porque tem passado a minha alma"13. Ao leitor, contudo, informa que o livro é uma despedida, pois reúne ali todas as produções poéticas de sua infância e adolescência publicadas em jornais como A luz, Echo Literário, para dedicar-se ao magistério: "São frutos dos 16 e dos 18 anos, que estavam abandonados e que vão percorrer o mundo, porque alguns amigos assim o quiseram". Além de professor primário, foi secretário da Comissão Executiva Permanente do Professorado, além de sócio-fundador da Associação Alfa Literária e da Sociedade Beneficente e Instrução e da Associação dos Professores de Lisboa ${ }^{14}$.

Antes de viajar para a Europa, foi um dos redatores do jornal $O$ Prisma, "órgão dedicado aos interesses da classe acadêmica", fundado em Ouro Preto no ano de 1890. Além disso, colaborou em muitos periódicos e revistas, como o O Lorense e o Echo Municipal de São Paulo, O Estandarte, Ensino Primário, O Lincoln, a Gazeta da Tarde, o Guanabara e A Revista do Brasil, onde foi encarregado da seção literária e de crônicas, a Revista literária dirigida por Mauricio Teixeira e a Revista Pedagógica. Contudo, apesar dessa intensa atuação, não publicou alguns de seus trabalhos, como o Compêndio de Geografia, o que não se deu porque teria grande número de estampas, que dariam grande despesa. Por sua vez, o autor teria recusado apresentar a Gramática Portuguesa ao Conselho Diretor da Instrução 
Pública para um parecer, alegando que não gostaria de ter seu trabalho subordinado aos programas das escolas públicas, que mudavam anualmente ${ }^{15}$.

A singularidade de Luiz Augusto dos Reis reside nas múltiplas motivações e sentidos de sua complexa experiência enquanto poeta, escritor, professor primário, redator de jornal, funcionário público. Essa trajetória permite concordar com a análise na qual os autores apontam que:

A visibilidade adquirida pelo professor Luiz Augusto dos Reis no campo educacional e na imprensa da capital do Império, provavelmente, contribuiu para a indicação de seu nome como integrante da comissão de professores primários designada para realizar a viagem pedagógica aos países estrangeiros, já no início do governo republicano. ${ }^{16}$

A bordo do vapor italiano Rejina Margherida, partiu Manoel Frazão rumo à Europa. Desembarcou em Gênova, em 17 de dezembro, com a incumbência de visitar escolas na França, Bélgica, Suécia, Suíça, Alemanha e Inglaterra. Imbuído da compreensão de que o exercício dessa missão envolvia observar, registrar, comparar e propor, ainda no início da viagem, diante da organização do trabalho nas salas de aula, das atividades pedagógicas desenvolvidas, dos objetos escolares e, em particular, dos usos do tempo nas escolas que observava em Roma, permitiu-se indagar:

Como é possível que os pobres professores do Rio de Janeiro possam apresentar resultados em suas escolas se elles são obrigados a ensinar em três classes, muitas vezes não tendo adjunto, e sendo além disso privados do descanço dos intervallos, pois que nelles devem ensinar a Musica e a Gymnástica? Quem muito abarca, pouco abraça ${ }^{17}$

Antes da viagem, escrevia intensamente na imprensa, proferia palestras em Conferências Pedagógicas, preocupava-se com a organização do magistério, em associações profissionais, como o Instituto Profissional de Professores, participara da Sociedade dos Amantes da Instrução e articulara o Manifesto dos Professores Públicos (1871).

Desde 1860, começou sua trajetória, marcada pelo combate em defesa dos interesses do magistério. Autor de Cartas do Professor da Roça, publicadas, em 1863, originalmente no jornal O Constitucional, criado pelo Partido Conservador para fazer frente às teses liberais, denunciar os limites do projeto e dos defensores do mesmo, Manoel Frazão teria suas car- 
tas publicadas em um opúsculo no ano seguinte, quando era vice-diretor e professor do Colégio Barão de Tautphous e exercia a docência como professor público ${ }^{18}$.

Visto na historiografia como um professor com afinidades e relações com o projeto conservador, Manoel Frazão, ao embarcar, levava na bagagem uma vasta experiência como autor de compêndios, de métodos de ensino e pareceres. Sua indicação para integrar a Comissão de Professores Primários à Europa e aos Estados Unidos, no que sua trajetória permite perceber, significou um reconhecimento ao trabalho desenvolvido em favor da educação.

Certo esquecimento paira sobre Amélia Ferreira da Costa, que, diferentemente de Frazão e do próprio Reis, não foi merecedora de pesquisas e verbetes biográficos em dicionários sobre educadores, mulheres e personagens ilustres ${ }^{19}$. No entanto, uma entrevista concedida por Antenor Nascentes, filólogo, nascido em 17 de junho de 1886, a Pedro Bloch, no qual relatava sua escolarização em fins do século XIX, dá pistas do prestígio que ela tinha nos meios educacionais. Tendo sido aluno de Amélia, lembrou:

Meu pai tinha um superior na Alfândega, cuja esposa era professora na Rua da Quitanda. Ao saber do sucedido, propôs que eu fosse para aquela escola. Fui. Ali, D. Amélia Fernandes da Costa me deu provas do que podem uma grande mestra e um coração de mulher. Fui um dos aprovados, com distinção, no exame final realizado na Benjamin Constant; tão miúdo, ainda, que precisava alcançar o alto do quadro-negro na ponta dos pés, provocando gargalhadas dos examinadores. Ao terminar o primário, ela, diante da pobreza de meu pai, se prontificou a me ajudar para que pudesse fazer o secundário. Consegui matrícula gratuita e continuei o meu rosário de distinções. Pois D. Amélia, ainda que sentindo imensa alegria, nunca me fez um elogio. Jamais ouvi dela palavra de louvor. Nem era preciso. Seu olhar dizia tudo. ${ }^{20}$

Amélia Fernandes da Costa, por sua vez, visitou inicialmente as escolas de Gênova, em sua viagem empreendida em finais de 1890, afirmando que não faria um trabalho minucioso, o que reservaria para o relatório final. Diferentemente dos colegas da comissão, não informa em seu relato datas de embarque, sendo menos detalhista nesse aspecto. Posteriormente, visitou Milão, Turim e Paris. Em suas proposições, procurará se aproximar da realidade educacional deixada em seu país imbuída da importância de propor mudanças. Provavelmente, estava convenci- 
da do novo significado que as viagens ganhavam naquele momento, impulsionadas por um projeto republicano mais amplo de modernização da sociedade, inspirado em modelos trazidos de países considerados mais avançados.

Como se pode depreender, os professores comissionados foram escolhidos em função do reconhecimento que possuíam nos meios intelectuais e educacionais. Por isso, provavelmente, quando regressaram, tiveram espaço assegurado na Revista Pedagógica para relatar suas impressões de viagens, que, atendendo às justificativas e finalidades da missão oficial, privilegiavam a organização escolar, a organização do magistério, o material didático, a arquitetura das escolas e aspectos relativos à remuneração dos professores.

\section{Para além das obrigaç̃ões das viagens}

Entre as obrigações dos viajantes estava a escrita de um relatório de viagem, escrita esta que não se esgotou nas obrigações daquele que viajava pela comissão, mas se transformou em partilha dos conhecimentos e impressões pessoais e, até mesmo, íntimas daquele que escreve.

Nas palavras de Luiz Augusto dos Reis, a viagem em si era uma incumbência de confiança, destinada a poucos, "Só hoje, infelizmente, posso dar-vos conta do meu trabalho no desempenho da honrosa e árdua comissão que me foi confiada"21. Apesar de as palavras do relatório serem direcionadas "ao Sr Inspetor", uma autoridade, é possível que o próprio autor do relatório o tenha escrito pensando em outros leitores.

O pertencimento à referida comissão é apontado como motivo de orgulho, apesar de se constituir em árdua tarefa. Uma viagem para a Europa, em finais do século XIX, significava um peso e, ao mesmo tempo, uma experiência desafiadora para um professor primário brasileiro, capaz de funcionar como um divisor de águas, um marco na trajetória profissional e pessoal desse sujeito, para além da ideia de distinção entre os demais no campo educacional, significado este traduzido por Reis no poema "Antes de partir"22: 
Sonhar! Sempre sonhar! Deixar que a phantasia

Ébria, doida, a voar, me leve a novos mundos!

Fazer do vasto oceano a enorme travessia!

Calmo,fitar do alto os pélagos mais fundos!

Deixar que entrem n'um barco um bando de esperanças

Collocar sobre um lenho um ninho de illusões,

$\mathrm{E}$ ir longe, muito longe, em nome das crianças,

Aprender a formar os grandes corações.(...)

Que sagrada missão! Que invejavel destino!

Ir mandado por ti - ó carta do a-b-c,

Por ti que és do progresso o escudo adamantino,

Ó deusa em que na Terra o mundo inteiro crê!

Ir mandado por ti visitar velhos templos

Onde hauriram saber as fortes gerações!

Recolher, pressuroso, os fúlgidos exemplos!

Mestres do velho Mundo, ouvir vossas lições! (...)

Ainda que direcionado a uma autoridade, o autor evidencia as dificuldades para a escrita de um relatório enquanto se viaja, manifestando o peso das muitas atribuições da referida comissão:

Tendo chegado a Lisboa em meados de janeiro, eu só deveria escrever o meu primeiro relatório trimestral em fins de abril. Para ganhar tempo, livrando-me do primeiro desses relatórios parciais, verdadeiro incomodo para quem está em viagem, sem o sossego preciso nem acomodações próprias para o preparo de um trabalho capaz, eu resolvera desempenhar-me desse compromisso mesmo antes da época fixada, ficando completamente apto para fazer um estudo demorado e refletido sobre as escolas publicas da grande capital. ${ }^{23}$

Uma viagem à Europa representava, também, as posições políticas do viajante. Assim, o relatório de Manoel Frazão sugere que a viagem significou para ele uma possibilidade de "autoformação, de aprendizagem e, sobretudo, de produção de um discurso de mediação cultural, por meio do uso de estratégias de apropriação e de (re)interpretação das idéias, dos saberes e dos modelos pedagógicos em circulação nos ditos países civilizados"24. Nessa perspectiva, é possível ler suas observações sobre a realidade visitada com permanente interesse em interferir nos destinos da realidade educacional brasileira. 
Significou, também, para ele - que aceitou o convite para integrar a comissão como uma missão natural para quem dedicara a vida à missão de educar -, um espaço para prosseguir não só na defesa dos interesses dos "pobres professores do Rio de Janeiro", como já assinalado, mas, também, para exercitar a crítica ao governo, como pode ser visto desde a primeira página que dá o tom ao seu relato, publicado na Revista Pedagógica, na qual aponta as imprecisões contidas na própria legislação que criava a comissão que integrava, particularmente do artigo $5^{\circ}$ das instruções que regulamentavam a viagem, que não deixavam claro quando deveria encaminhar os objetos comprados:

Eis uma questão que não seria de nenhuma importância se tratasse de um único comissionado, porque à administração seria indifferente receber estes objectos juntos, ou separados. Porem,com a pluralidade de enviados, acontecerá que nos interpretarão de um modo, outros, de outro, e dessa divergência poderão surgir confrontos injustos e desagradáveis. (...) Remetterei trimestralmente o que houver coleccionado, salvo um ou outro caso de excepção. Si a autoridade competente julgar que não é correcto o meo modo de proceder, adverir-me-há; e eu obedecerei. ${ }^{25}$

Como o de seus companheiros de comissão, o relatório de Amélia Ferreira da Costa, publicado na Revista Pedagógica, permite compreender que o interesse pelo outro e pelas viagens no século XIX não se manifestava somente entre os europeus, sendo muitos os casos de latinoamericanos que embarcavam com destinos e intenções variados, como as viagens de estudantes a Coimbra ${ }^{26}$ ou ainda mulheres escritoras, cujos relatos "são interessantes por abordarem temáticas pouco examinadas pelos viajantes masculinos" 27 .

Refletindo sobre a importância da viagem empreendida, ela a considerava uma oportunidade de, a partir do conhecimento de outras experiências de ensino, propor e sugerir mudanças na educação em seu país. Para além das atribuições de cada membro da referida comissão, em seus escritos, transparece especial interesse pelos museus pedagógicos, pela instrução feminina, infantil e de adultos, sobretudo em dias e horários alternativos, como à noite ou aos domingos, por exemplo ${ }^{28}$.

Diante dos poucos registros existentes sobre sua trajetória, o que indica que ocupava um lugar menos proeminente na cena pública, até então reservada aos homens, é possível pensar que essa viagem tenha sig- 
nificado uma forma de romper com o anonimato, conferir um novo sentido à sua existência e dar visibilidade à sua experiência profissional.

Para os três viajantes, escrever sobre o que viram no estrangeiro, em terras distantes, implicou um permanente exercício de distanciamento físico, intelectual e emocional, propiciando ao leitor de hoje compreender que as viagens empreendidas por professores em finais do século XIX apresentavam uma série de especificidades, o que exige uma análise que leve em conta as condições de produção do relatório, além de adentrar por inúmeros aspectos, entre os quais as estratégias de divulgação adotadas.

\section{A publicização das viagens}

A dimensão pública das viagens da comissão se expressa na divulgação na Revista Pedagógica ${ }^{29}$, publicação mensal do Pedagogium, órgão criado por Benjamin Constant que funcionou de 1890 a 1919, no Rio de Janeiro, como uma das mais importantes iniciativas e inovações pedagógicas republicanas e que visava à transformação da sociedade, tomando o modelo educacional francês como exemplo a ser seguido ${ }^{30}$, e cuja finalidade se definia na letra da lei:

constituir-se em centro impulsor das reformas e melhoramentos de que carece a instrução nacional, oferecendo aos professores públicos e particulares os meios de instrução profissional de que possam carecer, a exposição dos melhores métodos e do material de ensino mais aperfeiçoado. Conseguirá este fim mediante: a boa organização e exposição permanente de um Museu pedagógico; conferências e cursos científicos adequados ao fim da instituição; gabinetes e laboratórios de ciências físicas e naturais; concursos; exposições escolares anuais; direção de uma escola primária modelo; instituição de uma classe-tipo de desenho e de oficinas de trabalhos manuais; organização de coleções-modelo para o ensino científico concreto nas escolas públicas; publicação de uma Revista pedagógica (...). (Decreto n. 667, 16 de agosto de 1890)

Além de divulgar a viagem, no seu primeiro número, na seção oficial, na matéria “Commissão de professores primários á Europa e aos Estados Unidos da América do Norte”, a Revista citava os nomes dos professores que viajavam, dedicava um bom espaço para a publicação dos 
relatórios trimestrais dos três professores ${ }^{31}$, além de indicar a leitura avulsa dos mesmos ${ }^{32}$.

A publicação desses relatórios de viagens estava referida a um projeto editorial da Revista Pedagógica que pretendia dar visibilidade às iniciativas educacionais que ocorriam mundo afora. Desde o primeiro número, na Seção "Chrônica do exterior", estavam artigos sobre a educação na Alemanha, Argentina, Áustria, Bélgica, Chile, Costa Rica, Dinamarca, Espanha, Estados Unidos da América do Norte, França, Grécia, Inglaterra, Itália, Japão, México, Portugal, Rússia, Romênia, Suíça, Turquia e Uruguai. É possível inferir que a veiculação de experiências educacionais desenvolvidas em outros lugares, considerados mais avançados, funcionasse como argumento de autoridade para as inovações que se pretendia implantar em nosso país, no momento em que se delineavam os rumos a serem seguidos pela educação republicana.

Tal publicação mostra que a Revista Pedagógica começava, assim, a desempenhar papel significativo na produção de saberes ligados à educação e, consequentemente, na constituição do campo disciplinar pedagógico, veiculando um discurso educacional cada vez mais especializado. Por suas páginas, a educação passava não só a ser vista como problema social, mas como tendo papel estratégico na superação do atraso e na promoção do progresso no Brasil ${ }^{33}$.

Primeiro periódico oficial do governo republicano especializado em questões educacionais, criado com a finalidade de padronizar administrativa e pedagogicamente a escola, e no qual ocorreu um cruzamento entre medicina, escolarização e civilização, veiculando um discurso que pretendia prescrever uma rotina a ser seguida na escola para que se obtivesse um homem e uma sociedade regenerados ${ }^{34}$, possivelmente foi apropriado de modos muito diversos por seus leitores, ávidos por notícias do Velho Mundo, item de que esses relatórios de viagens eram, também, portadores.

O relatório de viagem de Manoel Frazão ganhou, ainda, o formato de livro, com 516 páginas e nove gravuras, que mereceu destaque no periódico:

É uma obra de rigoroso methodo, abundante em úteis informações, e ungida de entusiasmo que só o amor profissional consegue dar.

Recomendamo-la ao estudo de nossos collegas e á consulta de nossos legisladores. 
A' parte algumas apreciações demasiado severas e conclusões um pouco precipitadas, encontrarão ahi discutidas magistralmente interessantes questões do ensino publico primário, na actualidade.

Os capítulos referentes: Ao trabalho manual e A educação na escola constituem preciosas monographias que pretendemos incluir, data venia, na Bibliotheca especial do Pedagogium.

O Sr. professor Frazão fechou, portanto, com chave de ouro a série dos trabalhos da Commissão de três membros enviados à Europa em fins de 1890 . Nós o congratulamos de coração e nos ufanamos em rememorar as honrosíssimas palavras do ilustre Mr. Otto Salomon:

Si todos os professores do Brasil teem as qualidades do Sr. Frazão, esse paiz é deveras afortunado! ${ }^{35}$

A divulgação do relatório de Luiz A dos Reis também não se limitou à Revista Pedagógica, onde teve publicação trimestral, em 1891. Ao todo, foram três edições. O relatório completo, contendo nove figuras e 648 páginas, foi publicado pela Imprensa Nacional, no ano de 1892. Além dessas duas edições, houve uma terceira, publicada pelo Pedagogium, em volume especial ${ }^{36}$. As diferentes edições do relatório remetem, ainda, ao entendimento das suas condições de escrita. A primeira parte, dedicada à visita a Portugal, foi feita nesse país, ao passo que a parte final do relatório foi escrita após o retorno ao Brasil. O interesse na divulgação desse relatório, por sua vez, pode ser interpretado como uma prestação de contas ao governo, que financiou a viagem, e uma oportunidade para que os demais professores públicos e estudiosos da educação primária tomassem conhecimento das diferentes experiências de ensino em diversos países.

Ao longo de 648 páginas do relatório completo, o autor estrutura o trabalho em dois grandes blocos. O primeiro contempla as visitas a Portugal (mais demorada) e à Espanha, numa exposição sucinta e breve. $\mathrm{O}$ segundo bloco é dedicado à França e à Bélgica. Antes de descrever e relatar os aspectos que mais chamaram sua atenção nos referidos países, faz uma espécie de desabafo, expondo angústias e até mesmo revoltas. Com isso, é possível que entendamos suas condições de vida e as dificuldades inerentes à realização dos trabalhos e visitas nas escolas:

Deixando o Porto e seguindo para a Espanha, tive grandes dificuldades em encontrar em Madrid a Legação brasileira (...). Demais eu chegava em péssima ocasião a Madrid. Os preparativos para a festa de São Jose, o santo mais festejado em toda a Espanha, absorviam todas as atenções. Dois ou três dias depois desse grande dia popular, começavam as férias da semana santa, guar- 
dada nesse país com as maiores demonstrações de respeito, a ponto d estar fechado todo o comercio durante seis ou sete dias e não rodarem carros na rua durante a quinta, a sexta-feira e a manhã de sábado. ${ }^{37}$

Do relatório da Amélia Fernandes da Costa tem-se notícias apenas na própria Revista Pedagógica, nas recomendações e indicações de leitura: "Pedimos a atenção dos leitores para o interessante relatório da professora D Amélia Fernandes, publicado na seção pedagogia"38.

O primeiro relatório trimestral da professora Amélia F. da Costa foi escrito em Milão, no mês de março de 1891, e publicado no tomo II da Revista Pedagógica, nos meses de abril/setembro. Já o segundo relatório de Amélia foi também o último, publicado no tomo III da revista, anos 1891-1892: "No próximo número concluiremos o relatório da professora D Amélia Fernandes, publicaremos integralmente o do professor Frazão (...)".

\section{Um certo modo de ver e se deixar ver}

Os relatórios de viagens, em princípio escritos para cumprir obrigações, fogem dos padrões de neutralidade e objetividade que predominam em documentos produzidos com a finalidade de prestar contas. Transbordam da escrita desses viajantes suas escolhas e também suas tensões e emoções. A interrupção abrupta de uma viagem que deveria durar dois anos causou muita frustração em Luiz Augusto dos Reis:

Começara então o meu relatório, e dele á tinha escrito algumas linhas, quando a 9 do mesmo mês de abril fui surpreendido por um telegrama oficial, que declarava extintas todas as comissões de professores brasileiros, quer primários, quer secundários e superiores, que estavam na Europa. O primeiro nome citado no telegrama era o meu, sendo-me só permitido ficar, se entendesse que os meus vencimentos próprios eram suficientes, pois a gratificação mensal extraordinária, que me fora marcada, cessava daí em diante. A cessação da gratificação, cessação brusca e inesperada, não antecedera nem sequer uma prevenção, um aviso. ${ }^{39}$

Todavia, para além de um relato minucioso de tudo o que viu e observou nas escolas europeias, a escrita de Luiz Augusto dos Reis é marcada pela emoção e, sobretudo, pelas visões e impressões do autor. Seu 
texto não é um relato impessoal na terceira pessoa, mas uma narrativa pessoal: "Folgarei imenso se estiver enganado. O que posso desde já declarar é que vos direi neste relatório, franca e minuciosamente, tudo quanto vi em Portugal, Espanha, França e Bélgica"40.

Para ele, a notícia do término da viagem foi repleta de desgosto e desânimo diante de todo entusiasmo "para trabalhar no que era verdadeiramente da minha comissão: o estudo e reconhecimento minucioso das escolas da França, Bélgica, Suiça, Italia, Inglaterra e Suécia(...)"»11. Confessa que perdeu a coragem de dirigir-se às autoridades de ensino para visitar as escolas após o recebimento do telegrama, o que se agravou pela eminente falta de dinheiro em país estrangeiro:

Eu ficaria recebendo os parcos vencimentos da antiga tabela, que não davam para a minha manutenção e de minha família, quer estivesse lá comigo, como estava, quer tivesse ficado aqui na capital e com ela tivesse de despender metade dos vencimentos para mantê-la. Nessas condições, era impossível permanecer em país europeu estudando e muito menos viajar. ${ }^{42}$

Em contrapartida, o autor atribui à acolhida e às redes de apoio estabelecidas durante a viagem a força que teve para superar e tolerar as adversidades. Nesse sentido, são recorrentes as passagens em que cita nomes de instituições e, principalmente, pessoas que o acolherem e ajudaram em sua missão:

No desempenho da minha comissão em Lisboa fui imensamente auxiliado por um jovem e inteligente compatriota que ai reside com sua família, o sr João Francisco Lisboa, ex-discípulo do Dr Meneses Vieira, que para ele me deu uma carta de recomendação. A esse moço brasileiro devi o ser apresentado a varias notabilidades portuguesas, e seria falta imperdoável o não manifestar-lhe aqui o meu reconhecimento. ${ }^{43}$

Por mais que muitos aspectos observados na educação dos países visitados tenham sido previamente acordados e estabelecidos junto ao Inspetor da Instrução, as escolhas e marcas pessoais dos professores se manifestam no texto.

Assim, o olhar que Manoel Frazão lança sobre as escolas primárias, as escolas normais e os jardins de infância difere, em muitos aspectos, do tom defendido e acentuado por Amelia Fernandes da Costa em seus relatórios. Ele demonstra certa preocupação com a divisão entre 
sexos nas escolas e, principalmente, com as condições de ensino, quando parece posicionar-se com mais ênfase em relação às condições de trabalho do professor no Brasil, preocupação esta presente, como vimos, desde as Cartas de um Professor da Roça, em que escreveu:

Isso posto, quaes são os homens que entre nós se occupam do magisterio? Ou antes, é este entre nós uma profissão? Não! Nenhum homem que dispõe de um certo cabedal de conhecimentos deixa occupações muitissimo mais vantajosas, para dar-se á uma vida ingloria e penosa, a um sacerdocio todo de abnegação, como o magisterio!

Dos homens distinctos que conta hoje a classe (que os conta) uns são distrahidos com occupações de diversa ordem, e só dão ao magisterio a hora designada para leccionar, e isso mesmo nem sempre; outros fazem do magisterio uma ante-camara para esperarem os melhoramentos que almejam.

Commo leccionam os primeiros? Cançados de mil outros afazeres, qual atarefado da politica, qual dos trabalhos de sua repartição, que lhe absorveria todo o tempo, não é possivel que satisfaçam ás condições de um professor dedicado. De minimis non curat proetor. Vejamos os segundos. Estes, tendo sempre em mira melhorar de posição, estão attentos ao lado donde lhes acenam maiores vantagens.

Ora, esse estado anormal do espirito de uns e outros é incompativel com a assiduidade indispensavel ás lidas do magisterio! ${ }^{44}$

Sua escrita, que enfatiza a viagem como oportunidade de estudo, que envolvia experiências tão importantes, a ponto de, inclusive, atrasar a escrita do relatório ${ }^{45}$, se dá sempre na pauta da comparação e da proposição. Assim é que, ao concluir suas impressões sobre o ensino na Itália, que, a seu ver, é caracterizado pela divisão do trabalho, pela regularidade nos processos e pela disciplina do corpo, para a qual concorre "uma inspeção competente, única, que é respeitável e que póde ser efficaz”, ele pede licença para fazer outra reflexão de cunho pessoal:

Entre nós, a inspecção tem sido sempre feita por pessoas incompetentes, ainda que muito respeitáveis a todos os outros respeitos, digo mal, sob todos os outros respeitos, digo mal, sob os outros pontos de vista. Os nossos inspectores escolares forão todos muito honrados, muito justos, e e muito illustrados, muito zelosos, e muita cousa mais; porém; não entendiam do ensino. ${ }^{46}$

Mesmo não sendo um relato autobiográfico stricto sensu, em muitos momentos Frazão deixa escapar traços de sua personalidade, como se pode ver na ênfase dada à boa acolhida que teve na Itália e ao sucesso de 
uma de suas conferências, escrita em francês, traduzida para o italiano e que lera para um grande público. Esse registro sugere, além de uma intenção de legitimar-se ainda mais na cena educacional e junto às autoridades brasileiras, certa vaidade:

O effeito foi muito além da expectativa.Tive uma verdadeira ovação, póde-se dizer que capitaneada pelo Sindaco, que tomando depois a palavra, pronunciou-se de um modo honrosíssimo para mim. (...)

Para nada omittir, acrescentarei que mimoseei as autoridades e outras pessoas que me honraram com sua benevolencia, com exemplares especiaes da minha conferencia, como esses que remetto para serem entregues às autoridades de meu paiz. Informado pelo digno Sindaco, de que o rei de Itália não desgostaria de ver meu trabalho, pedi que lhe fizesse chegar às mãos um exemplar. $\mathrm{O}$ generoso magistrado, pela muita honra que em tudo me quis fazer, remetteume a carta que mandára de Roma o secretario particular do seu soberano, acompanhando-a de uma sua.

Guardo-as ambas como uma recordação feliz, e uma consolação suave no meio das amarguras da minha triste situação. ${ }^{47}$

Por sua vez, Amélia Fernandes da Costa demonstra particular interesse pela condição mulher-mãe-professora, ironizando a dominação masculina na educação, em que "Quase todas as escolas de Turim são dirigidas por homens, se bem que o ensino seja quase todo confiado a senhoras" ${ }^{\prime 4}$. Tal questionamento não aparece nos relatórios produzidos pelos professores Frazão e Reis, e pode ser compreendido, aqui, como parte da própria experiência de Amélia enquanto mulher casada, professora e mãe $e^{49}$. As escolhas, nesse caso, parecem também evidenciar mais do que determinações e obrigações de escrita. Adentrando ainda mais por seu relato, temos outros elementos reveladores de seu interesse pela educação dos pobres, das crianças e das mulheres, em parte assim esboçado:

Os jardins de infância também seriam de muita utilidade entre nós, pois, como vemos tantas vezes, quando precisamos de uma criada em nossas casas, ou havermos de suportá-la com um ou dois filbinhos, que ainda não tenham idade conveniente para frequentar escolas públicas, ou ficará ela sem empregar-se, por não ter onde deixar os filhos, ou ainda dará quase todo o seu ordenado a uma pessoa conhecida que se encarregue das crianças enquanto ela desempenha os deveres de que se incumbiu, tornando-se para elas, estas pobres e inocentes criancinhas, apesar de toda a ternura e amizade maternas, uma verdadeira carga que mal lhe permite prover aos meios de vesti-las e calça-las. ${ }^{50}$ 
Nesse trecho, é possível vislumbrar não somente o ponto de vista da professora como também o da Amélia mulher e dona de casa, preocupada e, ao mesmo tempo, incomodada com um problema cotidiano habitual que poderia ser resolvido caso houvesse, no Brasil, jardins de infância que "viriam suprir essa lacuna". Para ela, a existência de jardins infantis anexos às escolas femininas seria a salvação para o problema da mulher-mãe, "obrigada a ganhar com o seu trabalho o pão e vestiário para seus filhos" $"$.

Em que pese uma escrita também na primeira pessoa, seu relatório é o mais impessoal dos três. Diferentemente de Frazão e Reis, ela não se permite divagar sobre dificuldades, imprevistos e surpresas da viagem. Não fala do frio. Não trata de sua saúde. Não expõe frustrações. Não formula propostas de modo tão contundente ou explícito como seus companheiros de comissão, mas nada escapa ao seu olhar atento. Registrou, com muitos detalhes e adjetivos, tudo o que observara nas escolas. Mesmo com sua escrita mais contida, mais prudente, talvez com menos veleidades literárias ou, quem sabe, uma atitude feminina de mais censura sobre a esfera do privado e mais cautela no trato da coisa pública, deixa-se mostrar.

\section{Quase uma conclusão}

Podemos dizer que os viajantes estavam longe apenas fisicamente da própria terra, pois a cada nova cidade ou escola visitada aproximavam-se mais de perto da realidade educacional do país. Não se limitavam a observar e anotar. Perscrutavam, comparavam, propunham, com a intenção de provocar mudanças nos rumos que a política educacional brasileira deveria tomar.

Relatar o visto e o vivido em terras estranhas significou para eles uma experiência de formação que envolveu um exercício de introspecção e um modo de desnudar-se para deixar vir a público, além de seus descontentamentos e suas críticas, suas esperanças.

Os relatórios de viagem constituíram-se, assim, em modos muito próprios de interferir nos destinos da educação daqueles que não se esconderam na impessoalidade da escrita obrigatória. 


\section{REFERÊNCIAS}

AUGEL, M. P. Visitantes estrangeiros na Babia oitocentista. São Paulo: Cultrix/MEC, 1980. BASTOS, Maria Helena Câmara. Pro patria laboremus: Joaquim José de Menezes Vieira (1848-1897). Bragança Paulista: EDUSF, 2002.

BASTOS, Maria Helena Câmara. O Pedagogium registros de memórias da educação no Brasil (18901919). Actas do VII Congresso Luso-Brasileiro de História da Educação, Porto, Faculdade de Psicologia e Ciências da Educação (Universidade do Porto), 20 a 23 junho de 2008.

BELluZO, A. M. M. O Brasil dos Viajantes. 3 ed. São Paulo: Metalivros e Objetiva; Salvador: Fundação G. Odebrecht, 2000.

BITTENCOURT, Adalzira. Dicionário bio-bibliográfico de mulheres ilustres, notáveis e intelectuais. Rio de Janeiro: Editora Pongetti, 1969.

BLAKE, Sacramento. Dicionário bibliográfico brasileiro. Rio de Janeiro: Imprensa Nacional, 1899.

BORGES, Angélica. Nem tudo que reluz é ouro: representações docentes em relatório de uma viagem à Europa. (1890-1892). Disponível em:

$<$ www.sbhe.org.br/novo/.../Angelica\%20Borges\%20-\%20Texto.pdf>. Acesso em 15.8.2009. BRAZIL, Erico; SCHUMAHER, Schuma. Dicionário de mulheres do Brasil. Rio de Janeiro: Jorge Zahar, 2000.

CARTOLANO, Maria Thereza. Museus escolares, Pedagogium, Lições das Coisas: prenúncios da mentalidade científica na educação brasileira do final do século XIX. III SEMINÁRIO NACIONAL DE ESTUDOS E PESQUISAS "HISTÓRIA, SOCIEDADE E EDUCAÇÃO NO BRASIL”. Anais... Campinas: FEUNICAMP, 1996.

CHARTIER, Roger. As práticas da escrita. In: ARIÉS, Philippe; CHARTIER, Roger. (org.) História da vida privada 3: da Renascença ao Século das Luzes. Tradução de Hildegard Feist. São Paulo: Cia das Letras, 1991. pp. 113- 161.

FERNANDES, Ana Lúcia Cunha. Educação, ciência e progresso: a revista pedagógica e o "problema social" do Brasil no final do século XIX. Revista Contemporânea de Educação, Publicação on line do Programa de Pós-Graduação em Educação da UFRJ, n. 1, abril 2006. FRANCO, Stela Maris. Peregrinações de outrora: viajantes latino-americanas no século XIX. Florianópolis: Ed mulheres; Santa Cruz do Sul: EDUNISC, 2008.

FLORES, Hilda Agnes. Dicionário de Mulheres. Porto Alegre: Nova Dimensão, 1999.

GONDRA, José. Ao correr da pena: reflexões relativas às cartas de professores do século XIX. In: MIGNOT, Ana Chrystina V.; CUNHA, Maria Teresa C. (Orgs.) Práticas de memória docente. São Paulo: Cortez, 2002.

GONDRA, José. Ecos da República: ciclo de vida e doutrina médica da Revista Pedagógica (1890-1896). Educação On-line. p. 12. Disponível em:

$<$ www.educacaoonline.pro.br>.

GONDRA, José. O Veículo de Circulação da Pedagogia Oficial da República: a revista pedagógica. Revista Brasileira de Estudos Pedagógicos, v. 78, n. 188/189/19, p. 374-395, 1997. GRAHAM, Maria. Diário de uma viagem ao Brasil e de uma estada nesse país durante parte dos anos de 1821, 1822 e 1823. São Paulo: Ed. Nacional, 1956.

LEITE, Miriam L Moreira. Livros de viagem (1803-1900). Rio de Janeiro: UFRJ, 1997.

MARTINS, Luciana de Lima. O Rio de Janeiro dos viajantes: o olhar britânico : 1800-1850.

Rio de Janeiro: J. Zahar, 2001. 
MAUSS, Marcel. Ensaio sobre a Dádiva. Sociologia e Antropologia. São Paulo: EPU, 1974. MIGNOT, Ana Chrystina V.; GONDRA, José (Orgs). Viagens Pedagógicas. São Paulo: Cortez, 2007.

O ENSINO PUBLICO PRIMÁRIO EM PORTUGAL, ESPANHA, FRANÇA E BÉLGICA, pelo professor Luiz Augusto dos Reis. Rio de Janeiro, Imprensa Nacional, 1892.

MIGNOT, Ana Chrystina; CUNHA, Maria Teresa C. (Orgs.) Práticas de memória docente. São Paulo: Cortez, 2002.

O ENSINO PUBLICO PRIMÁRIO NA ITÁLIA, FRANÇA E BÉLGICA pela professora D Amélia Fernandes da Costa. Rio de Janeiro, Imprensa Nacional, 1891.

O ENSINO PUBLICO PRIMÁRIO NA ITÁLIA, SUÍÇA, SUÉCIA, BÉLGICA, INGLATERRA E FRANÇA pelo professor Frazão. Rio de Janeiro, Gazeta de Noticias.

O PRISMA: órgão dedicado aos interesses da classe acadêmica. Ouro Preto, MG: Typ. do Movimento, 1890.

PEDRO BLOCH ENTREVISTA ANTENOR NASCENTES. Disponível em: $<$ http://www.filologia.org.br/xcnlf/17/08.htm>. Acesso em 6.8.2009.

REIS, Luiz Augusto dos. Cantos e prantos. Rio de Janeiro: Livraria de A. T. de Castro Dias editor, 1874.

REIS, Luiz Augusto dos. Os exames na China. Revista Pedagógica, Rio de Janeiro, set./dez. 1894.

REIS, Luiz Augusto dos. A influencia da escola sobre a educação dos alunos. Revista Pedagógica, Rio de Janeiro, mar./set. 1895.

SALGUEIRO, Valéria. Grand Tour: uma contribuição à história do viajar por prazer e amor à cultura. Revista Brasileira de História. Viagens e viajantes. São Paulo, ANPUH, v. 22, n. 44, 2002.

SCHUELER, Alessandra. A longa peregrinação de um professor da roça na Europa. In: MIGNOT, Ana Chrystina V.; GONDRA, José (Orgs.) Viagens pedagógicas. São Paulo: Cortez, 2007.

SCHULER, Alessandra. Combates por uma escola moralizada e cívica: a experiência do professor Manoel José Pereira Frazão na corte imperial (1870-1880). Revista Brasileira de História da Educação. Campinas: Autores Associados, n. 9, jan./jun. 2005.

SCHUELER, Alessandra; GONDRA, José. Olhar o outro, ver a si: Um professor primário brasileiro no 'Velho Mundo' (1890-1892). In: Revista Brasileira de História da Educação: Dossiê Viagens de Educadores, Circulação e Produção de Modelos Pedagógicos, Jan. 2010, n 22.

REVISTA PEDAGÓGICA: publicação mensal do Pedagogium. Tomos I a IX.

SILVA, Innocencio Francisco da. Dicionário Bibliográfico Português. v. XVI. Lisboa, Imprensa Nacional, 1961.

SUSSEKIND, Flora. O Brasil não é longe daqui: o narrador, a viagem. São Paulo: Companhia das Letras, 2000.

VIÑAO, Antônio. Relatos e relações autobiográficas de professores e mestres. In: MENEZES, Maria C. (Org.). Educação, memória, história: possibilidades, leituras. Campinas (SP): Mercado de Letras, 2004.

VIÑAO, Antônio. Las autobiografias, memórias y diários como fuente histórico-educativa: tipologia y usos. Teias - Revista da Faculdade de Educação. Rio de Janeiro, UERJ, n. 1 , jun. 2000. 


\section{NOTAS}

1 A respeito de viagens de educadores, consultar: MIGNOT, Ana Chrystina; GONDRA, José G. (Orgs.) Viagens Pedagógicas. São Paulo: Cortez, 2007.

2 A primeira comissão de professores, designada em 28 de outubro de 1890, “contava com dois professores da Faculdade de Medicina do Rio de Janeiro, um da Escola Politécnica, um do Ginásio Nacional (designação republicana do Imperial Colégio de Pedro II), um do Instituto Benjamin Constant, um do Instituto Nacional de Música e, finalmente, quatro professores públicos do ensino primário da capital. Dentre estes, foram nomeados os professores Luiz Augusto dos Reis, Manoel José Pereira Frazão, Amélia Fernandes da Costa e Adelina Doyle e Silva, sendo que apenas os três primeiros seguiriam viagem para o Velho Mundo. Da viagem realizada pelos professores primários resultaram relatórios, apesar do incidente ocorrido com o corte das verbas e dos subsídios concedidos pelo governo em abril de 1891, o que ocasionou o retorno antecipado dos professores Luiz Augusto dos Reis e Amélia Fernandes da Costa”. Cf: SCHUELER, Alessandra; GONDRA, José. Olhar o outro, ver a si: Um professor primário brasileiro no "Velho Mundo" (1890-1892). Revista Brasileira de História da Educação: Dossiê Viagens de Educadores, Circulação e Produção de Modelos Pedagógicos (prelo), que resulta de mesa-redonda apresentada na Universidade de Porto, por ocasião do VII Congresso Luso Brasileiro de História da Educação.

3 A respeito da literatura de viagens e dos usos dos relatórios de viagem como fonte para a história da educação, consultar VIÑAO, Antonio. Las autobiografias, memórias y diários como fuente histórico-educativa: tipologia y usos. Teias - Revista da Faculdade de Educação. Rio de Janeiro, UERJ, n. 1, p. 82-97, jun. 2000.

4 Revista Pedagógica. Tomo I, anos 1890/1891, p. 21.Grifos nossos.

5 A este respeito, Valéria Salgueiro mostra como surge no século XVIII um novo tipo de viajante, que dispondo de tempo e dinheiro, viajava por puro deleite e "amor à cultura”. In: SALGUEIRO, Valéria. "Grand Tour: uma contribuição à história do viajar por prazer e amor à cultura". Revista Brasileira de História. Viagens e viajantes. São Paulo, ANPUH, n. 44, v. 22, 2002.

6 Para aprofundar os estudos sobre viajantes no século XIX, consultar: LEITE, Miriam L Moreira. Livros de viagem (1803-1900). Rio de Janeiro: UFRJ, 1997; MARTINS, Luciana de Lima. O Rio de Janeiro dos viajantes: o olhar britânico-1800-1850. Rio de Janeiro, J. Zahar, 2001; SUSSEKIND, Flora. O Brasil não é longe daqui: o narrador, viagem. São Paulo: Companhia das Letras, 2000; BELLUZO, A. M. M.. O Brasil dos Viajantes. 3 ed. São Paulo: Metalivros e Objetiva; Salvador: Fundação G. Odebrecht, 2000; AUGEL, M. P. Visitantes estrangeiros na Babia oitocentista. São Paulo: Cultrix/MEC, 1980.

7 MAUSS, Marcel. "Ensaio sobre a Dádiva". In: Sociologia e Antropologia. São Paulo: EPU, 1974.

8 A respeito da viagem de Manoel Frazão e Luiz Reis, consultar: BORGES, Angélica. "Nem tudo que reluz é ouro: representações docentes em relatório de uma viagem à Europa.(1890-1892)". Texto disponível em: www.sbhe.org.br/novo/.../Angelica\%20Borges\%20-\%20Texto.pdf; Ver também: 
SCHUELER, Alessandra. A longa peregrinação de um professor da roça na Europa, In: MIGNOT, Ana Chrystina V. e GONDRA, José (Orgs). Viagens pedagógicas. São Paulo: Cortez, 2007, pp. 90-113. Sobre a viagem de Luiz Augusto Reis, consultar: SCHUELER, Alessandra $e$ GONDRA, José. (op. cit).

9 Relatório do Professor Luiz A. dos Reis. Revista Pedagógica, Tomo II, p. 277-279; $355-$ 427, 1891.

10 Primeiro relatório trimestral do Professor M. J. Pereira Frazão. Revista Pedagógica, Tomo II, p. 163-190, 1891.

11 Relatório trimestral da Professora Amélia F. da Costa. Revista Pedagógica, Tomo II, p. 105-147, 1891.

12 REIS, Luiz Augusto. O ensino público primário em Portugal, Espanha, França e Bélgica - Escolas primárias elementares e superiores maternas, profissionais, normais, asilos e jardins infantis, museus pedagógicos, etc. In: Relatório apresentado à Inspetoria Geral de Instrução Publica da Capital Federal: Rio de Janeiro: Imprensa Nacional, 1892. p. 7.

13 REIS, Luiz A. Dedicatória. In: REIS, Luiz A. Cantos e prantos. Rio de Janeiro: Livraria de A T de Castro Dias Editor, 1874.

14 BLAKE, Sacramento. Dicionário bibliográfico brasileiro. Rio de Janeiro: Imprensa Nacional, 1899. p. 366-367.

15 BLAKE, Sacramento. Dicionário bibliográfico brasileiro. Rio de Janeiro: Imprensa Nacional, 1899. p. 366-367.

16 Ver SCHUELER; GONDRA (2007).

17 FRAZÃO, M. J. Pereira. Primeiro Relatório Trimestral. Revista Pedagógica. Tomo II, p. 179, 1981. (Grifo no original)

18 A respeito desta publicação de Manoel José Pereira Frazão, ver: GONDRA, José. Ao correr da pena: reflexões relativas às cartas de professores do século XIX. In: MIGNOT, Ana Chrystina V.; CUNHA, Maria Teresa C. (Orgs.). Práticas de memória docente. São Paulo: Cortez, 2002; Sobre Manoel José Pereira Frazão, ver SCHUELER, Alessandra. Combates por uma escola moralizada e cívica: a experiência do professor Manoel José Pereira Frazão na corte imperial (1870-1880). Revista Brasileira de História da Educação. n. 9, jan./jun. Campinas: Autores Associados, 2005, p. 109-138; SCHUELER, Alessandra. A longa peregrinação de um professor da roça na Europa. In: MIGNOT, Ana Chrystina V.; GONDRA, José (Orgs.) (op. cit.).

19 Procuramos, sem êxito, informações sobre Amélia Fernandes da Costa nos seguintes dicionários biográficos: BITTENCOURT, Adalzira. Dicionário bio-bibliográfico de mulheres ilustres, notáveis e intelectuais. Rio de Janeiro: Pongetti, 1969; BLAKE, Sacramento. Dicionário bibliográfico brasileiro. Rio de Janeiro: Imprensa Nacional, 1899; FLORES, Hilda Agnes. Dicionário de Mulheres. Porto Alegre: Nova Dimensão, 1999; BRAZIL, Erico; SCHUMAHER, Schuma. Dicionário de mulheres do Brasil. Rio de Janeiro: Jorge Zahar, 2000 .

20 Entrevista na íntegra em Pedro Bloch entrevista Antenor Nascentes. Disponível em: $<$ http://www.filologia.org.br/xcnlf/17/08.htm>. Acesso em 6 de agosto de 2009. 
21 REIS, Luiz Augusto. O ensino público primário em Portugal, Espanha, França e Bélgica-Escolas primarias elementares e superiores maternas, profissionais, normais, asilos e jardins infantis, museus pedagógicos, etc. Relatório apresentado à Inspetoria Geral de Instrução Publica da Capital Federal. Rio de Janeiro: Imprensa Nacional, 1892. p. 7. 22 Poema publicado na Seção Variedade da Revista Pedagógica. Tomo III, p. 294-298, 1891-1892.

23 REIS, Luiz A dos. Ibidem. p. 149.

24 Cf, SHUELER, Alessandra. (op. cit), p. 110-111.

25 FRAZÃO, Manoel. (op. cit,) p. 163,164.

26 CARVALHO, José Murilo de. A Construção da ordem. A elite política imperial. Rio de Janeiro: Campus, 1980. O autor destaca um capítulo à formação dos estudantes oriundos do Brasil na Universidade de Coimbra (capítulo 3).

27 FRANCO, Stela Maris. Peregrinações de outrora: viajantes latino-americanas no século XIX. Florianópolis: Mulheres; Santa Cruz do Sul: EDUNISC, 2008. p. 25.

28 COSTA, Amélia Fernandes da. Relatório trimestral. Revista Pedagógica, Tomo II, p. 111, 1891.

29 Entre os estudos sobre a Revista Pedagógica destacamos: GONDRA, J. G. O Veículo de Circulação da Pedagogia Oficial da República: A Revista Pedagógica. Revista Brasileira de Estudos Pedagógicos. Brasília, v. 78, n. 188, 189, 190, p. 374-395, jan./dez. 1997; GONDRA, J.G. A Pedagogia da República: uma leitura do discurso oficial da revista Pedagógica (1890-1896). São Paulo: FEUSP, 1996. (Mimeo)

30 Ver BASTOS, Maria Helena Câmara. Pro patria laboremus: Joaquim José de Menezes Vieira (1848-1897). Bragança Paulista: EDUSF, 2002. Consultar, ainda, BASTOS, Maria Helena Camara. O Pedagogium registros de memórias da educação no Brasil (18901919). In: Actas do VII Congresso Luso-Brasileiro de História da Educação, Porto: Faculdade de Psicologia e Ciências da Educação (Universidade do Porto), 20 a 23 junho de 2008 e CARTOLANO, Maria Thereza. Museus escolares, Pedagogium, Lições das Coisas: prenúncios da mentalidade científica na educação brasileira do final do século XIX. Anais do III Seminário Nacional de Estudos e Pesquisas "História, Sociedade e Educação no Brasil". Campinas: FEUNICAMP, 1996.

31 Indicador bibliográfico. Revista Pedagógica. Tomo VI, ano 1894.

32 Indicador bibliográfico. Revista Pedagógica. Tomo VI, ano 1894.

33 Cf. FERNANDES, Ana Lúcia Cunha. Educação, ciência e progresso: a revista pedagógica e o "problema social” do Brasil no final do século XIX. Revista Contemporânea de Educação, Publicação on line do Programa de Pós-Graduação em Educação da UFRJ, n. 1, abril 2006. Para a autora, "A Revista Pedagógica desempenhou um papel fundamental, tanto na circulação quanto na produção de saberes (teorias, mas também idéias, modelos, práticas, experiências, etc.) ligados à educação e, conseqüentemente, na progressiva constituição de um campo disciplinar, no caso o pedagógico, por meio da veiculação de um discurso educacional cada vez mais especializado. Dito de outra forma, entende-se que a Revista ao mesmo tempo que veiculou tal discurso, ajudou, de forma decisiva, a 
construí-lo. O que se afigura aqui de mais significativo é exatamente a observação da Revista como objeto do qual emergiram processos de estruturação do próprio campo pedagógico, interessando perceber a conjugação entre as dimensões científica, política e educacional especializada, ou seja, de que maneira ocorreu a construção de um discurso em educação (numa dimensão científica), também portador de uma idéia de progresso (em sua dimensão política, que busca legitimar o Estado-Nação) e, ao mesmo tempo, com pretensões de especialização".

34 Cf. GONDRA, José Gonçalves. Ecos da República: ciclo de vida e doutrina médica da Revista Pedagógica (1890-1896). Educação On-line. p. 12. Disponível em: <www.educacaoonline.pro.br $>$. Para o autor, nesse cruzamento, permitia-se o comparecimento de temáticas sobre ginástica e mobiliário escolar, que "a doutrina médica participasse, ao mesmo tempo, da conformação e do ordenamento social e escolar”. GONDRA, J. G. O Veículo de Circulação da Pedagogia Oficial da República: a revista pedagógica. Revista Brasileira de Estudos Pedagógicos, v. 78, n. 188/189/19, p. 374-395, 1997. Segundo o autor, uma série de dificuldades orçamentárias afetaram a periodicidade da Revista Pedagógica, que, prevista para ser mensal, teve publicação irregular em 1892 e 1893 e trimestral, entre 1894 e 1896.

35 Cf. Relatório do professor Frazão. Revista Pedagógica. p. 147, 1892.

36 Conforme apurado em BLAKE, Sacramento. Dicionário bibliográfico brasileiro. Rio de Janeiro: Imprensa Nacional, 1899. p. 366-367.

37 REIS, Luiz A dos. O Ensino Publico Primário em Portugal, Espanha, França e Bélgica. Rio de Janeiro: Imprensa Nacional, 1892. p. 136.

38 Revista Pedagógica, p. 135, 1891.

39 REIS, Luiz A dos. Idem, p. 150.

40 REIS, Luiz A dos. Ibidem, p. 150.

41 Ibidem.

42 Ibidem.

43 Ibidem, p. 11.

44 O Constitucional, 21 de março de 1863. apud GONDRA. op. cit, p. 28.

45 Ibidem, p. 167. Teria cursado aulas com Otto Salomon, além de ter ministrado inúmeras conferências.

46 FRAZÃO, Manoel. Relatório. op. cit. p. 180.

47 Ibidem, p. 187-188, $2^{\circ}$ semestre 1891.

48 Ibidem. p. 159.

49 Amélia Fernandes da Costa era casada com José Ferreira Pinto da Costa e mãe de Domingos Fernandes da Costa. Em 1888, lecionava aulas particulares de "línguas e várias ciências" na Rua Gen. Câmara, 74, sobrado, conforme anúncio do Almanak Laermmert de 1888, p. 951.

50 COSTA, Amelia F. op. cit, p. 140.

51 Ibidem. 
Recebido: 17/08/2010

Aprovado: 22/11/2010

\section{Contato:}

Universidade do Estado do Rio de Janeiro Centro de Educação e Humanidades

Faculdade de Educação

Rua São Francisco Xavier, 524

$12^{\circ}$ andar - Bloco B - Sala 12019

Maracanã

Rio de Janeiro - RJ

CEP 20550-900 